\title{
Applicability of Low Frequency Transmission Technology in Offshore Wind Power Transmission Scene
}

\author{
Jian Yang ${ }^{1}$, Jing Ge G, $^{*}$, Zuofu Jiang ${ }^{3}$, Chi Zhang ${ }^{1}$, Jianhua $\mathrm{Lv}^{1}$, Guode $\mathrm{Ying}^{1}$, Haohua $\mathrm{Wu}^{4}$ \\ ${ }^{1}$ State Grid Taizhou Electric Power Supply Company, 31800, China \\ ${ }^{2}$ State Key Laboratory of Advanced Transmission Technology (Global Energy Interconnection Researching Institute Co., Ltd.), State \\ Grid Office Area, North District of Future Science and Technology City, Changping District, Beijing, 102200, China \\ ${ }^{3}$ Taizhou Hongchuang Electricity Group Limited Company, 318000, China \\ ${ }^{4}$ Taizhou Hongda Electric Construction Co., Ltd. Taizhou Economic Development Zone Operation And Mintenance Branch, 318000, \\ China
}

\begin{abstract}
This paper investigates the worldwide development status of wind power and the main opinions and advantages of offshore wind power development in the industry, and summarizes that the development of offshore wind power will be in the direction of large capacity and distant sea area. At the same time, the distribution of wind energy resources in China's coastal areas is investigated, and combined with the constraints of offshore wind energy development in China, it is concluded that offshore wind power development in China will also develop to distant sea areas. Secondly, three transmission modes including power frequency AC, flexible HVDC and low frequency AC are briefly described, and the technical economy of the three modes is analyzed with typical cases. In addition, the technical feasibility of $400 \mathrm{MW}$ offshore wind power Grid-connected through low-frequency transmission technology is verified by system model building and simulation. Thirdly, combined with the development trend of offshore wind power, current research and manufacturing level, the opportunities and challenges of the application of low frequency transmission technology are analyzed. Finally, the main points of this paper are summarized. It is preliminarily clear that the low-frequency transmission mode has better technical and economic performance within a certain transmission distance, and can be used as a beneficial supplement to the conventional power frequency and flexible HVDC transmission mode.
\end{abstract}

\section{Introduction}

In recent years, wind power has developed rapidly. According to the Global Wind Power Development Report 2017[1] issued by the Global Wind Energy Council, more than 90 countries in the world have carried out wind power commercialization business, of which 9 countries have installed more than $10 \mathrm{GW}$ wind power and 30 countries (Europe, Asia, North America, Latin America and Africa) have installed more than 1 GW wind power. By the end of December 2017, the total installed capacity of wind power in the world is 539.1 GW. The report predicts that the total installed capacity of wind power will reach $840 \mathrm{GW}$ by the end of 2022. In its Global Wind Power Development Report 2016[2], the Global Wind Energy Council predicted that in 2020 and 2030, the installed wind power in the world would reach $560 \mathrm{GW}$ and $1100 \mathrm{GW}$, respectively, and the generating capacity would reach 1.4 trillion $\mathrm{kWh}$ and 2.8 trillion $\mathrm{kWh}$, respectively.

In addition to land wind power, offshore wind power is developing rapidly and has a broad market. In 2016, the International Renewable Energy Agency (IRENA) published a report entitled Innovation Outlook: Offshore

\footnotetext{
${ }^{*}$ Corresponding author: gjsonia@sina.com
}

Wind[3], which assessed the future trend of the factors related to the rapid development of the offshore wind power industry. If the global economy has been developing towards a non-carbon direction, wind power will become the main power supply by 2030 . According to the International Renewable Energy Agency, the total installation of offshore wind power will reach $100 \mathrm{GW}$ by 2030 .

The development of offshore wind power industry now covers not only the Nordic region, but also North America, East Asia, India and other regions. In the foreseeable future, although Europe will continue to lead the offshore wind power market, the current trend shows that the global offshore wind power is likely to start to develop rapidly in the next few years.

Compared with onshore wind energy, offshore wind energy has the following advantages[4-6]:

(1) The offshore wind resources are abundant, and the wind speed is relatively stable, which is larger than the onshore wind power generation. Usually, the sea surface wind speed of $10 \mathrm{~km}$ offshore is about $25 \%$ larger than that of the coastal land, and is less affected by the environment. Wind resources can be used three times as much as that of the land. It is more conducive to the collection and conversion of wind energy resources. It 
has no great interference to human activities and reduces the cost of investment.

(2) The surface roughness of sea water is low, the friction force at sea level is small, and the wind speed varies little with the height. It does not need a high tower to reduce the cost of wind turbines.

(3) The turbulence intensity of offshore wind is low, and the fatigue load of wind action on wind turbines is reduced, thus prolonging the service life of wind turbines.

(4) Wind power technology has been relatively mature, with the most large-scale development and commercial development. Some European countries' offshore wind power has entered the commercial stage after 2001, and the technology will be gradually improved.

(5) The frequency of wind speed available for wind energy development in most of the world's sea areas is basically more than $60 \%$. That is to say, most of the world's sea areas can start wind power generation at least half of the year, while solar energy and other limited by daytime, the available time will not exceed $50 \%$.

Therefore, large-scale offshore wind power development has become the development direction of new energy utilization at home and abroad, and will develop towards large capacity, Far-sea and deep-water areas. The offshore wind power transmission technology is particularly important. Traditional power frequency transmission is only suitable for wind farms with small capacity and close offshore distance. Flexible DC technology can meet the needs of large capacity transmission, but its construction and maintenance costs are high. Low-frequency transmission technology can effectively improve the current carrying capacity of submarine cable and reduce terminal voltage fluctuation by reducing transmission frequency. It has good economy in a certain transmission distance. This paper will compare three kinds of offshore wind power transmission modes from technical and economic aspects, and give the applicable scope of each transmission mode.

\section{Development status and delivery technology analysis of offshore wind power}

\subsection{Recent development of offshore wind power in china}

In 2010, the National Climate Center simulated the distribution of wind energy resources at $70 \mathrm{~m}$ altitude in China's offshore waters as shown in Table 1. China's offshore wind energy resources are abundant, with the East China Sea being the most abundant of the four major sea areas, followed by the Bohai Sea, the South China Sea and the Yellow Sea. Among all the sea areas, the Taiwan Strait is the most abundant in wind energy resources, with an average wind speed of over $8.5 \mathrm{~m} / \mathrm{s}$ and over $9 \mathrm{~m} / \mathrm{s}$ in some areas; followed by Zhejiang coast, eastern coast of Guangdong and Liaodong Bay of Bohai Sea, with an average wind speed of over $8 \mathrm{~m} / \mathrm{s}$; the average wind speed of other sea areas is mostly above
$7.5 \mathrm{~m} / \mathrm{s}$; the wind energy resources in northern Beibu Gulf and central Yellow Sea are relatively poor, with an average wind speed of about $7 \mathrm{~m} / \mathrm{s}$. According to the wind power report of 2014, in the coastal areas of China, the wind energy reserves are $200 \mathrm{GW}$ in the areas of 525 meters deep and 50 meters high, and $500 \mathrm{GW}$ in the areas of 5-50 meters deep and 70 meters high[7].

From the analysis of Table 1, we can see that the sea area between Liaodong Peninsula and Korean Peninsula, the east of Bohai Bay and Leizhou Peninsula in Guangdong Province, and the sea area from Yangtze River estuary to Hangzhou Bay have abundant energy reserves. In addition, in recent years, China has put into operation offshore wind farms, but offshore areas are restricted by military, fishery, environmental protection and other factors, so the development of offshore wind energy in China will also be developed to distant areas.

Table 1 Distribution of offshore wind power resources in China

\begin{tabular}{|c|c|c|}
\hline Areas & $\begin{array}{l}\text { average } \\
\text { annual wind } \\
\text { speed } \\
(\mathrm{m} / \mathrm{s})\end{array}$ & $\begin{array}{l}\text { average wind } \\
\text { power } \\
\text { density } \\
\left(\mathrm{w} / \mathrm{m}^{2}\right)\end{array}$ \\
\hline Coastal Yellow Sea & $5 \mathrm{~m}: 7.0-$ & $250-450$ \\
\hline Shandong Peninsula and & & \\
\hline $\begin{array}{l}\text { Laizhou Bay } \\
\text { Weihai }\end{array}$ & $25 \mathrm{~m}: 8.0$ & \\
\hline $\begin{array}{l}\text { Coastal area of Eastern } \\
\text { Liaodong Peninsula }\end{array}$ & $5 \mathrm{~m}: 7.0-$ & $300-500$ \\
\hline $\begin{array}{l}\text { Dalian, Southern End of } \\
\text { Liaodong Peninsula } \\
\text { Liaodong Bay } \\
\text { Bohai Bay }\end{array}$ & $25 \mathrm{~m}: 8.0$ & \\
\hline $\begin{array}{l}\text { Offshore Jiangsu } \\
\text { North-central Jiangsu }\end{array}$ & $6.0-6.5$ & $250-400$ \\
\hline Southern Jiangsu & & $300-400$ \\
\hline $\begin{array}{l}\text { Zhejiang Offshore } \\
\text { Hangzhou Bay, Zhejiang } \\
\text { The rest of Zhejiang sea } \\
\text { area }\end{array}$ & $50 \mathrm{~m}: 8.0$ & $250-450$ \\
\hline $\begin{array}{l}\text { Fujian and northeastern } \\
\text { Guangdong }\end{array}$ & $50 \mathrm{~m}: 8.0$ & $300-800$ \\
\hline $\begin{array}{l}\text { The Eastern Sea Area of } \\
\text { Leizhou } \quad \text { Peninsula, } \\
\text { Guangdong }\end{array}$ & & $300-450$ \\
\hline Hainan & $6.5-7.5$ & $250-400$ \\
\hline Offshore of Guangxi & $\begin{array}{l}25 \mathrm{~m}: 6.0- \\
6.5 \\
50 \mathrm{~m}: 6.5- \\
7.5\end{array}$ & $250-450$ \\
\hline
\end{tabular}

According to the distribution of wind energy resources in China, the relevant departments of China have issued reports on offshore wind power development planning. In the letter of A Reply to the Planning of Offshore Wind Power in Fujian Province[8], it was pointed out that the State Energy Administration agreed that the total scale of offshore wind power planning in Fujian Province was 13.3 million kilowatts, including 17 wind farms in Fuzhou, Zhangzhou, Putian, Ningde and Pingtan. By the end of 2020, the installed scale of offshore wind power in Fujian Province would reach more than 2 million kilowatts and by the end of 2030 to more than 5 million kilowatts. Among the 17 wind farms planned in Fujian Province, the scale of each area varies from $100 \mathrm{MW}$ to $500 \mathrm{MW}$, and the voltage level is 220 $\mathrm{kV}$. The theoretical water depth developed recently is below 20 meters, and the theoretical water depth in the 
medium or long term is between 25 and 60 meters. The transmission distance of different wind fields varies greatly, the nearest is $1.6 \mathrm{~km}$, and the farthest is $70 \mathrm{~km}$.

The Development Plan of Offshore Wind Power in Guangdong Province(2017-2030) (Revision)[9] planned the development of offshore wind power from 2017 to 2030. The offshore distance is not less than 10 kilometers and the water depth is less than 50 meters. It is estimated that by the end of 2020, the installed capacity of offshore wind power will exceed 12 million kilowatts, and by the end of 2030, the installed capacity of offshore wind power will be about 30 million kilowatts. The province plans 23 offshore wind farm sites, 15 offshore wind farm sites in shallow waters (within 35 meters of water depth), 8 offshore wind farm sites in deep waters (35-50 meters of water depth), the nearest $10 \mathrm{~km}$ offshore distance and the farthest $170 \mathrm{~km}$ offshore. The installed capacity of a single wind farm varies from 100MW to 900MW.

China is rich in offshore wind power resources in Fujian, Guangdong and Guangxi, and the development of offshore wind power over medium and long distances has been included in the plan, which will be the main trend of offshore wind power development in the future.

\subsection{Analysis of existing offshore wind power transmission technology}

In recent years, offshore wind power development in China's offshore areas has entered a stage of large-scale and commercial development. There are two traditional modes of offshore wind power transmission and gridconnected.

\subsubsection{High voltage ac grid connection technology}

At present, high-voltage $\mathrm{AC}$ transmission is the main way of offshore wind farms, such as the British Matrix offshore wind farm, the East China Sea such as the East China Sea wind farm and so on. High voltage AC transmission needs to change the output voltage level of wind farm and three-phase $\mathrm{AC}$ submarine cable transmission[10]. Therefore, large capacity transformer must be used to change the output voltage level of wind farm. The structure of high voltage AC transmission system is shown in Figure 1. High-voltage AC technology is relatively mature, but such wind farms and integrated power grid coupling, will have interaction. Due to the use of cable transmission, the capacitive reactance and inductance of lines, especially the relatively large capacitance of submarine cables to the ground, need reactive power compensation. Therefore, high voltage AC transmission is only suitable for shortdistance wind power transmission[11-12].

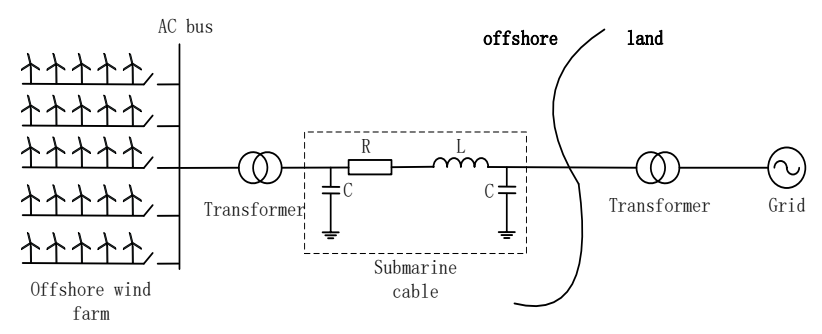

Fig. 1. High voltage AC transmission

\subsubsection{Flexible DC grid-connected technology}

The structure of flexible DC transmission system is shown in Fig. 2. Because there is no reactive power compensation problem in $\mathrm{DC}$, there is no limit on transmission distance, so it is more suitable for longdistance power transmission[12-14]. In addition, the general high voltage DC cable is also less than threephase $\mathrm{AC}$, the cost of the cable is relatively reduced. However, the use of high-voltage direct current transmission requires the conversion of power generated by offshore wind turbines, and the establishment of converter stations at sea and on land for power transmission[15]. In this way, the cost and maintenance cost of HVDC transmission are greatly increased. Especially, the construction difficulty, cost and maintenance cost of offshore converter station are much higher than that of land converter station.

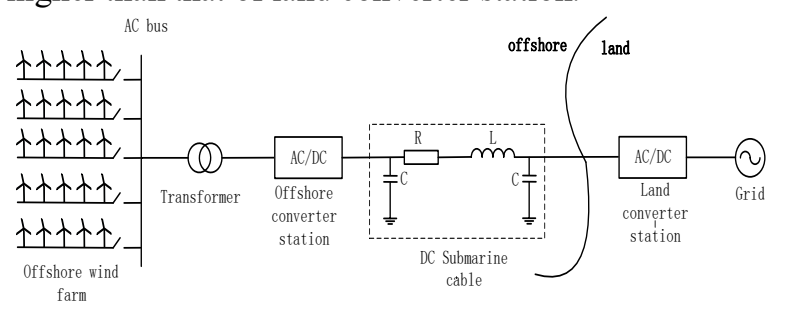

Fig. 2. Flexible DC transmission

Therefore, with the development of China's construction of offshore wind farms with large capacity and long distance, the traditional $\mathrm{AC}$ offshore wind power transmission technology will no longer meet the transmission demand, while the grid-connected HVDC transmission system has low practical application cost because of its high cost and complex operation and maintenance.

\section{Technical analysis of low frequency offshore energy delivery}

In view of the shortcomings of two traditional offshore wind power transmission technologies, low-frequency transmission technology is proposed for large-capacity offshore wind power transmission in the middle and distant sea areas.

\subsection{Interconnection of low-frequency offshore power transmission}

The structure of a typical offshore low frequency 
transmission system is shown in Figure 3. Lowfrequency power is generated by offshore wind turbines, boosted by offshore transformers and transmitted to land AC switching stations via submarine cables, then converted to power frequency by frequency conversion devices and integrated into power grid[16-20]. Compared to HVDC system, it can save the platform of offshore converter station, and its construction cost and maintenance cost are greatly reduced[21-25].

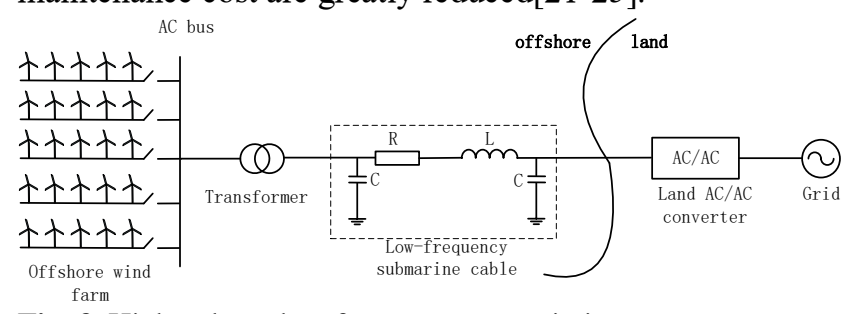

Fig. 3. High voltage low frequency transmission

\subsection{Comparison of low frequency and conventional ac delivery mode}

By reducing transmission frequency, low frequency transmission system can reduce line reactance and ground capacitance, thus reducing line charging current and shortening electrical distance. Taking $275 \mathrm{kV}$ offshore wind power grid connection as an example, two different types of cables are used to calculate. When the transmission distance reaches $100 \mathrm{~km}$ and $175 \mathrm{~km}$ respectively at $50 \mathrm{~Hz}$, the charging power will occupy the transmission capacity of the whole line and the transmission active power is 0 , if the transmission frequency is $15 \mathrm{~Hz}$, the charging power will be reduced effectively, as shown in Figure 4. Foreign scholars also have similar research, reducing the transmission frequency, the transmission active power decline rate greatly reduced[26].

In addition, the low-frequency transmission system can effectively reduce the terminal voltage fluctuation. Taking the $10 \mathrm{kV}$ voltage level and $150 \mathrm{~mm} 2$ submarine cable as an example, before the voltage fluctuation reaches the limit, the maximum active power transmission under the low-frequency $(15 \mathrm{~Hz})$ condition is 1.43 times of the power transmission limit.

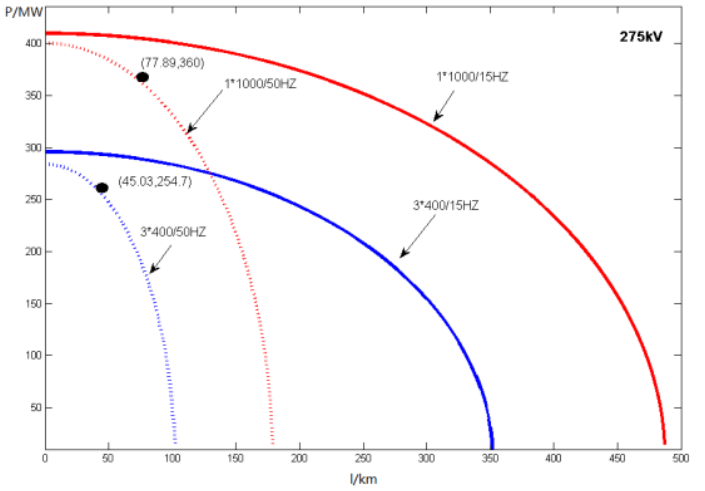

Fig. 4. 275kV Cables transmission power to length

\subsection{Comparison of low frequency and flexible dc delivery mode}

Flexible DC transmission mode does not have the restriction of transmission distance, but the cost is high. In this paper, two different cases of wind power convergence in deep water are considered. When low frequency transmission or flexible HVDC transmission are used to realize the interconnection of offshore wind power, their primary investment budgets are calculated and compared with each other economically. Generally speaking, there is no offshore converter in low frequency mode, and the cost of offshore converter valve and platform is omitted. However, the low frequency mode is still AC three-phase transmission. Compared with the straight poles, the cost of cable is higher than that of DC. Therefore, low-frequency transmission will have economic advantages when the distance is less than a certain economic distance. Especially with the increase of water depth, the economic advantages of low frequency $\mathrm{AC}$ transmission are more obvious.

Following will be a specific example of lowfrequency and flexible economy of comparative analysis.

According to ENSTO-E's Report on Offshore Transmission Technology[27], the average installed capacity of the current European offshore wind farms is 400-500 MW. The voltage level of flexible HVDC transmission system is $\pm 320 \mathrm{kV}$ (corresponding $\mathrm{AC}$ convergence voltage level is $275 \mathrm{kV}$ ). In order to facilitate comparison, the voltage level of low frequency transmission system is $275 \mathrm{kV}$, and the influence of charging power can be neglected when the transmission frequency is $15 \mathrm{~Hz}$.

Under the scenario of $400 \mathrm{MW}$ wind power outgoing and water depth of 30 meters, the funds for both are detailed in Table 2.

Table $2400 \mathrm{MW} / 30$ meters depth funding comparison (All costs are given in 100 millions of Yuan)

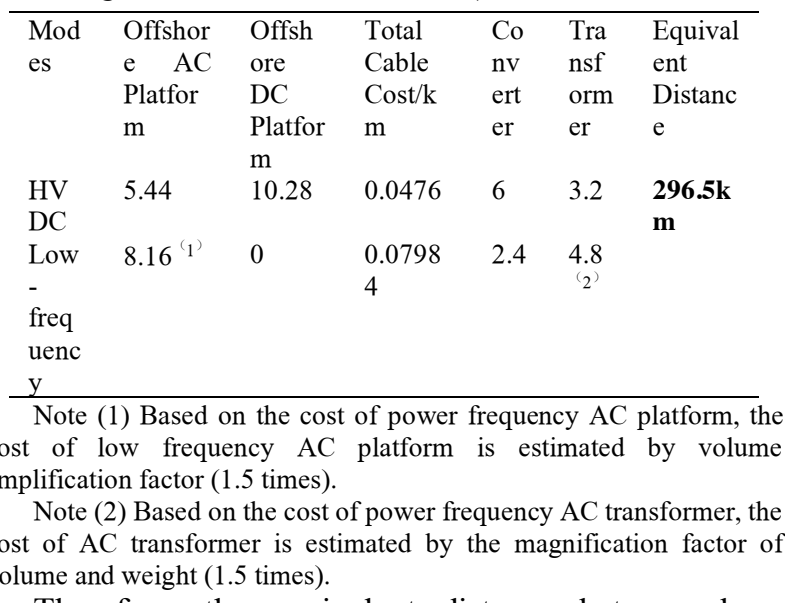

Therefore, the equivalent distance between lowfrequency AC and flexible DC in this case is 296.5 kilometers, when it's less than the distance, Lowfrequency $\mathrm{AC}$ has more economic advantages.

Water depth is an important factor affecting the cost of offshore platforms. The change of water depth conditions will also change the economic distance between the two modes. Under the scenario of $400 \mathrm{MW}$ wind power outgoing and 50 meters water depth, the funds for both are detailed in Table 3 . 
Table $3400 \mathrm{MW} / 50$ meters depth funding comparison (All costs are given in 100 millions of Yuan)

\begin{tabular}{lllllll}
\hline Mod & Offshor & Offshor & Total & Co & Tra & Equival \\
es & e AC & e DC & Cable & nv & nsfo & ent \\
& Platfor & Platfor & Cost/k & ert & rme & Distanc \\
& m & m & m & er & r & e \\
HV & 6.3232 & 12.322 & 0.0476 & 6 & 3.2 & $\mathbf{3 4 7 . 3 k}$ \\
DC & & & & & & m \\
Low & 9.4848 & 0 & 0.0798 & 2.4 & 4.8 & \\
- & $\left({ }^{1}\right)$ & & 4 & & $(2)$ & \\
freq & & & & & & \\
uenc & & & & & & \\
fen
\end{tabular}

$$
\mathrm{y}
$$

Note (1) Based on the cost of power frequency AC platform, the cost of low frequency AC platform is estimated by volume amplification factor (1.5 times).

Note (2) Based on the cost of power frequency AC transformer, the cost of AC transformer is estimated by the magnification factor of volume and weight (1.5 times).

Therefore, the equivalent distance between lowfrequency $\mathrm{AC}$ and flexible $\mathrm{DC}$ in this case is 347.3 kilometers, when it's less than the distance, Lowfrequency $\mathrm{AC}$ has more economic advantages.

To sum up, the grid-connected transmission mode of offshore wind farms can be selected by three ways: conventional $\mathrm{AC}$, low-frequency $\mathrm{AC}$ and flexible DC. Its technical feasibility distance and economic distance are affected by the capacity, water depth, voltage level, cable cross-section area and model of different wind farms. The optimal transmission mode should be selected according to the specific parameters of wind farms. Generally speaking, when the wind farm capacity is small and the offshore distance is relatively close (generally rated capacity is less than $200 \mathrm{MW}$, offshore distance is less than $100 \mathrm{~km}[28]$ ), it is suitable to adopt the conventional AC transmission mode. The transmission distance is short, which can ensure that the voltage fluctuation meets the standard. At the same time, the charging reactive power on the transmission line is within the required range, and there is no need to build offshore or land converter stations, which has low construction cost and maintenance. When the wind farm capacity is large and the offshore distance is less than $100 \mathrm{~km}$ to $250 \mathrm{~km}$, it is suitable to adopt low frequency AC transmission mode. On the premise of ensuring voltage fluctuation and charging reactive power to meet the requirements, only one end of land converter station needs to be constructed, which greatly reduces the cost of offshore platform and converter station compared with flexible DC transmission mode, and consequently reduces the maintenance cost and has significant economic advantages. If the offshore wind farm is far away from the shore and exceeds the economic distance of the low frequency transmission mode, the flexible DC transmission mode is suitable.

\section{Technical applicability analysis of low frequency offshore wind power delivery technology}

In order to verify the technical feasibility of offshore wind power transmission through low frequency, a simulation model of $400 \mathrm{MW}$ fan grid-connected system based on $\mathrm{M} 3 \mathrm{C}$ converter valve was built on PASCAD simulation platform.

The system parameters are shown in Table 4, in which the $\mathrm{Y}$ side is power frequency network and the $\mathrm{X}$ side is $15 \mathrm{~Hz}$ low frequency network. The system can realize low frequency wind power Grid-connected function.

Table 4 System parameters

\begin{tabular}{|c|c|c|c|}
\hline \multicolumn{2}{|c|}{ Equipm } & Parameters & Figure \\
\hline \multicolumn{4}{|l|}{ ent } \\
\hline \multirow{2}{*}{\multicolumn{2}{|c|}{$\begin{array}{l}\text { M3C converter } \\
\text { valve }\end{array}$}} & Rated capacity $/ M W$ & 400 \\
\hline & & Rated current $/ k A$ & 0.75 \\
\hline & & Capac-itance & 2.4 \\
\hline & & Voltage $/ k V$ & \\
\hline & & Submodule Capac-itance $/ m F$ & 5 \\
\hline & & Number of Submodules in & 190 \\
\hline & & Converter Chain & \\
\hline & & Carrier Frequency/HZ & 600 \\
\hline & & Current limiting reactance $1 / H$ & 0.038 \\
\hline & & Current limiting reactance $2 / H$ & 0.1 \\
\hline \multirow{3}{*}{$\begin{array}{l}\mathrm{Y} \text {-side } \\
\text { system }\end{array}$} & $\mathrm{AC}$ & Frequency/HZ & 50 \\
\hline & & Phase voltage $/ k V$ & 120 \\
\hline & & Phase current $/ k A$ & 1.125 \\
\hline \multirow{3}{*}{$\begin{array}{l}\mathrm{X} \text {-side } \\
\text { system }\end{array}$} & $\mathrm{AC}$ & Frequency/HZ & 15 \\
\hline & & Phase voltage $/ k V$ & 120 \\
\hline & & Phase current $/ k A$ & 1.125 \\
\hline
\end{tabular}

The system control algorithm structure includes: 1) outer loop active/reactive power control algorithm; 2) inner loop current decoupling control algorithm; 3 ) outer loop global voltage control algorithm; 4) link modulation wave generation algorithm (including DC voltage control and link DC control); 5) PWM signal generation algorithm.

The system control algorithm can be realized, 1) maintaining the constant active/reactive power of transmission; 2) bidirectional flow of converter energy; 3 ) decoupling control of active/reactive current; 4) decoupling control of frequency $\mathrm{x}$ side of $\mathrm{Y}$ side; 5) active power balance of $\mathrm{Y}$ side/ $\mathrm{x}$ side; 6) ensuring the stability of DC voltage of each link section at rated value.

The simulation results are as shown in figure 5 .

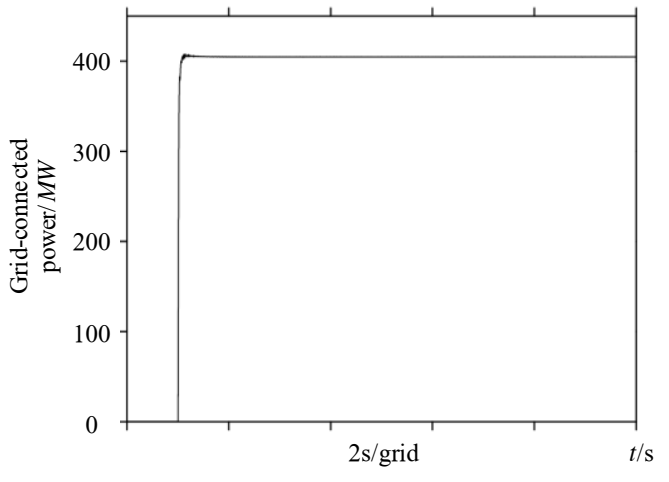

(a)

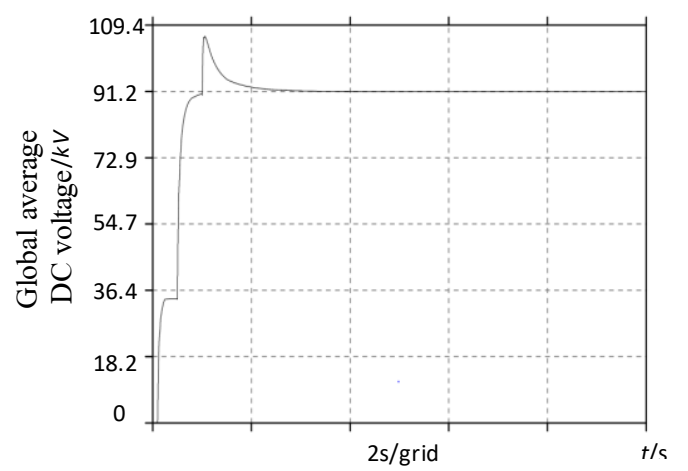


(b)

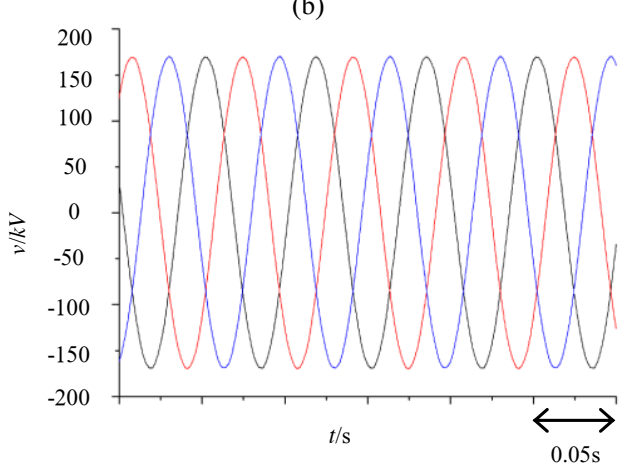

(c)

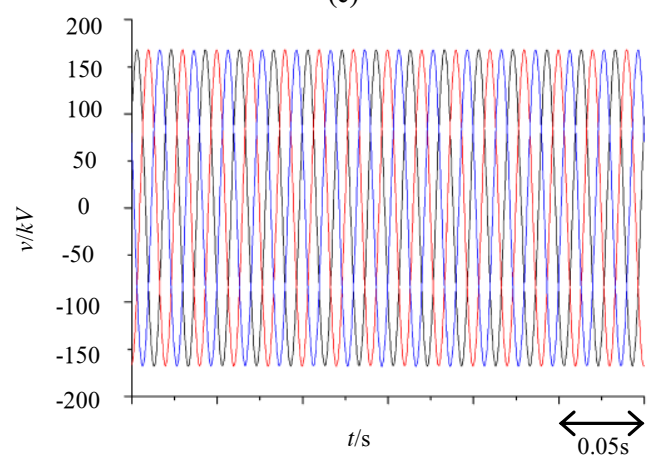

(d)

Fig. 5. Steady-state simulation waveform of offshore wind power Grid-connected system: (a) Grid-connected power and (b) Global average DC voltage and (c) Low-frequency voltage and (d) Power-frequency voltage.

\section{Opportunities and challenges of low frequency offshore wind power transmission}

Using low-frequency transmission mode to realize largescale and long-distance offshore wind power transmission can greatly improve the available capacity of submarine cables, and in a certain range of distance, compared with flexible DC transmission mode, the economic advantages are outstanding. From other application scenarios, due to the characteristics of lowfrequency transmission technology, it is conducive to the interconnection of multi-terminal network in the islands, and other scenarios such as offshore platform power supply, power supply in remote areas, capacity expansion and transformation of existing lines, improving transmission capacity of lines, increasing power supply radius, avoiding new lines, saving investment and construction. The transmission and power supply problems in the above typical scenarios bring opportunities for the development of lowfrequency transmission, a new type of transmission technology.

Through the above analysis, although the lowfrequency transmission technology has good technical economy, at present, there are still many technical breakthroughs to be made in practical application.

(1) Low frequency modification of fan side. The offshore wind power low-frequency delivery system described in this paper needs to be reformed at the wind turbine side to achieve low-frequency power generation.
The specific implementation method can reduce the gear box speed ratio, simplify the structure of wind turbine, change the operating conditions of wind turbine units, and improve efficiency. Although this method can further reduce the cost of fans, the specific implementation still needs to fully communicate with the fans manufacturers.

(2) Large capacity AC/AC converter. At present, frequency conversion technology is often used in motor drive, but there is no actual development and application of high voltage and large capacity $\mathrm{AC}$ converter. Moreover, the number of bridge arms of $\mathrm{AC}$ converter based on matrix transformation technology is large and the control process is complex. It is necessary to further study the main electrical parameters and control and protection strategies in combination with application scenarios, device capacity, frequency characteristics and system operation mode.

(3) Primary equipment for low frequency use. At present, the conventional primary equipment is designed according to the power frequency condition. When the frequency decreases, the diameter of the transformer core will increase. At the same time, the flux density of the transformer core will increase with the frequency decreases, leading to saturation of the core easily, distortion of the output waveform, increasing the volume of the core and reducing the flux density of the core are effective ways to avoid this phenomenon. Therefore, in low frequency environment, transformers are required to increase the volume of the core and reduce the flux density of the core. Insulation and structure design need to be re-evaluated; in low frequency environment, the switching time of circuit breaker will be significantly longer than that of power frequency, and the arcextinguishing ability in this process needs to be further studied; finally, under low frequency fault conditions, the ability of lightning arrester to release energy and valve plate needs to be re-evaluated.

\section{Conclusion}

(1) The development of offshore wind energy will become an important part of global energy development, and will develop towards large capacity and far sea area.

(2) Considering China's energy structure and the distribution of offshore wind energy resources, we should vigorously promote the development of wind energy in the middle and long distance sea areas of Zhejiang and Jiangsu.

(3) The combination of low-frequency transmission technology and offshore wind power transmission has better technical economy in a certain distance. It can be a beneficial supplement to conventional power frequency $\mathrm{AC}$ and flexible HVDC transmission technology.

(4) Low-frequency transmission technology needs further research and promotion. On the one hand, it needs to carry out frequency optimization and networking scheme research in combination with specific scenarios. On the other hand, it needs to cooperate with equipment manufacturers to further study the impact of frequency reduction on primary equipment. 


\section{References}

1. Global Wind Energy Council. Global Wind Report 2017. Belgium: Global Wind Energy Council, 2018:15-27.

2. Global Wind Energy Council. Global Wind Report 2016. Belgium: Global Wind Energy Council, 2017:1-2

3. International Renewable Energy Agency. Innovation Outlook: Offshore Wind. Abu Dhabi: International Renewable Energy Agency, 2016:52-95.

4. Liu Yong, Kong Xiangwei, Bai Ke. A Perspective Study On Technical Support System For Building Large Scale Offshore Wind Farm. Resources Science,2009; 31(11): 1862-1869.

5. Tan Zhizhong, Liu Deyou, Wang Feng, Yang Zhi. Planning Of Offshore Wind Farms. Shanghai Electric Power, 2007; 2:125-128.

6. Liu Qi, Xu Yi-Qing. Some Problems On Offshore Wind Power Development In China. Shanghai Electric Power, 2007; 2:144-148.

7. Fd.Bjx.Com.Cn. Development Status Of Global Offshore Wind Power In 2015 [Online]. Available: Http://News.Bjx.Com.Cn/Html/20160704/7477392.Shtml. 2016.

8. National Energy Administration. A Reply To The Planning Of Offshore Wind Power In Fujian Province. China: National Energy Administration, 2017:1-2.

9. Guangdong Development And Reform Commission. Development Plan Of Offshore Wind Power In Guangdong Province(2017-2030). China: Guangdong Development And Reform Commission. 2018:7-17.

10. G. B. Power Transmission Over Long Distances With Cables. Presented At: 2004 Cigre.

11. Ning Lianhui, Wang Xifan, Teng Yufei. Experiment On Wind Power Grid Integration Via Fractional Frequency Transmission System. Proceedings Of The Csee, 2011; 31(21): 9-16.

12. Chang Yong, $\mathrm{Xu}$ Zheng, Zheng Yuping. A Comparison Of The Integration Types Of Large Wind Farm. Automation Of Electric Power System, 2007; 31(14):70-75.

13. Jiang Hao, Sun Yu, Liu Hui. Literature Review Of Wind Power Integrated Into Power Systems With Hvdc-Flexible. North China Electric Power, 2017; 1: $1-7$.

14. Wei Xiaoguang, Tang Guangfu, Wei Xiaoyun, Chi Yongning. Study Of Vsc-Hvdc Controller To Mitigate Voltage Fluctuation Caused By Wind Farm Integration. Transactions Of China Electrotechnical Society, 2007; 22(4) :150-156.

15. Wu Jun-Hong, Ai Qian. Research On Multiterminal Vsc-Hvdc System For Wind-Farms. Power System Technology, 2009; 33(4): 22-27.
16. Wang Xifan, Wang Xiuli, Teng Yufei. Fractional Frequency Transmission System And Its Applications. Proceedings Of The Csee, 2012; 32(13): 1-6.

17. Chi Fangde, Wang Xifan, Wang Xiuli. New Wind Power Grid Connection Method Based On Fractional Frequency Transmission System. Automation Of Electric Power Systems, 2008; 32(4): 59-63.

18. Cho Y, Cokkinides G J, Meliopoulos A P. LfacTransmission Systems For Remote Wind Farms Using a Three-Phase, Six-Pulse Cycloconverter. In: Ieee Power Electronics And Machines In Wind Applications(Pemwa), IEEE, 2012: 1-7.

19. Teng Yufei, Ning Lianhui, Li Gan. Electromechanical Transient Caculation Method And Transient Characteristics Analysis Of Power System With Fractional Frequency Wind Power System. Automation of Electric Power System, 2015; 39(2):67-73.

20. Zhanf Kaoshe, Wang Jianhua, Yao Lixiao. Study On Steady-State Performances Of Power System Containing Fractional Frequency Transmission Lines. Power System Technology, 2001; 25(5):1014.

21. P. B. Wyllie Y T L R. Low Frequency Ac Transmission - Elements Of a Design For Wind Farm Connection. Presented At: 2015 11th Iet International Conference On Ac And Dc Power Transmission.

22. Wang Xifan. Fractional Frequency Power Transmission System. Electric Power, 1995; (1):2-6.

23. Wang Xifan, Wang Xiuli. Study Of Digital Simulation for Fractional Frequency Transmission System. Electric Power, 1995; (3):8-12.

24. Wang Xiuli, Wang Xifan, Wang Jianhua. The Initial Experiment Of Fractional Frequency Transmission System. Electric Power, 1996; (6):33-36.

25. $\mathrm{Hu}$ Chaofan, Wang Xifan, Cao Chengjun. Feasibility Research Of Flexible Fractional Frequency Transmission System. High Voltage Engineering, 2002; 3:16-18.

26. Achara, P. And T. Ise. Operating Phase And Frequency Selection Of Low Frequency Ac Transmission System Using Cycloconverters. Presented At: 2014 Power Electronics Conference (Ipec-Hiroshima 2014 - Ecce-Asia).

27. European Network Of Transmission System Operators For Electricity. Offshore Transmission Technology Report. Belgium:European Network Of Transmission System Operators For Electricity. 2011:35-44.

28. Chen Xia. Wind Power Integration Using MultiTerminal Hvdc Technology. Wuhan: Huazhong University Of Science And Technology, 2012; 57 . 